\section{Military Technical College Kobry El-Kobbah, Cairo, Egypt}

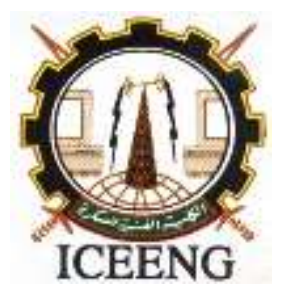

\author{
$11^{\text {th }}$ International Conference \\ on Electrical Engineering \\ ICEENG 2018
}

\title{
IOT-BASED SMART BUILDING MANAGEMENT SYSTEM
}

M. Kareem Ashraf *, Ihab Adly ** and Khaled A. Shehata ***

\begin{abstract}
This paper aims to optimize the usage and consumption of energy in Building Management System (BMS) based on Internet of Things (IoT), fuzzy logic algorithm. Smart meters and other sensing devices will be responsible for the data gathering. Single Board Computer (SBC) used as a web application to control and monitor the energy usage patterns for the connected devices. Also, this paper demonstrates the design and development of fuzzy logic technology. As a result, it delivers faster solutions than the conventional control design. A/C motor speed and lighting system are controlled by fuzzy algorithm according to measurements from temperature and occupancy sensors. MATLAB-simulation is used to achieve the designed goal. OPNET network simulator also has been used to provide an accurate understanding of system performance.
\end{abstract}

\section{KEY WORDS}

Building Management System, Internet of Things, Fuzzy logic algorithm, Single Board Computer.

\section{Introduction}

The Internet of Things (IoT) is an emerging concept of everyday objects interconnected with each other [1]. Day by day, the technology is becoming an increasingly important part of our everyday life but to actually automate a building is still a quite expensive job [2]. This leads us to the question why revert to smart building although it is expensive. First, building automation brings interoperability: the temperature can be set to a certain value according to certain conditions, lighting can be turned on/off or may be dimmed based on motion detection. Second, building automation implies remote access, such as monitoring the building using a laptop or even cell phone. Finally, a smart building automation system should have the possibility to be extended or reduced when needed. Therefore, it can bring expandability and energy savings [2][3].

\footnotetext{
* Arab Academy for Science, Technology and Maritime Transport, Cairo, Egypt.

** CEO, Tegrom, Egypt.

*** Dean of the Faculty of Engineering (Cairo Branch), Arab Academy for Science, Technology and Maritime Transport, Cairo, Egypt.
} 
Nowadays, one of the hottest topics in media is related to energy conservation. The rate of residential building investments has grown rapidly due to the general population growth [4]. Most of these buildings were erected without paying attention to the environmental consideration, which led to using active air conditioning to achieve thermal comfort. As a result, building energy consumption has been increasing to meet the requirements of cooling and electric lighting, as $52 \%$ of total electricity consumption goes to residential spaces [4]. So, solving the problem of energy waste in these buildings will have positive effects on user outcome and will be part of solving the energy crisis.

Several studies in this field are as follows: In [5] a Small Smart Home System, it was designed and implemented by utilizing WLAN network based on Arduino microcontroller. The system can monitor and control lights, room temperature, alarms and other household appliances. In [6] an individual control home automation system using Intel Edison board was differentiated in two separate categories. One is controlled locally and the other is controlled remotely by internet connection, which allows the user to control their system by devices such as smart phone, personal computer, or by using telephone gadget from the provider of home security. In [7] a Smart building with a safety system was used to save energy and reduce manual effort using various sensors and WiFi. This system could help users automatically turn on fans and light based on the current respective sensor values and hence reduces manual interventions.

This paper has been developed by using fuzzy logic control to get a solution of the false detection of motion sensor and the relationship between multi parameter and nonlinear control model for the motor speed of $A / C$ to overcome these drawbacks in the conventional design of the previous studies.

This paper offers a BMS with fuzzy logic algorithm developed in C language and realized using microcontroller to enable the system to monitor and control lights, room temperature, detect suspicious movements, automate on/off lighting system and other appliances. The next section discusses the fuzzy logic algorithm and its benefits to the system while the other sections discuss the proposed system architecture, the testing setup and network analysis of the system. Finally, this paper closes with a conclusion.

\section{FUZZY BASED BMS}

This research aims to increase capability of fuzzy logic control systems in automation process with potential benefits. One of the benefits of fuzzy control is that it has been extended to handle the concept of partial truth, where the truth value may range between completely true and completely false. Fuzzy logic imitates the logic of human thought, contrary to traditional logic theory which has two-valued logic: true or false. The objective of using fuzzy logic is to make the computer think like people. Using fuzzy logic algorithm enables machines to understand and respond to human concept such as hot, cold, large, small, etc. [8]. MATLAB-simulation is used to achieve the designed system. 


\section{A. Fuzzy Controller design for Motor Speed of Air Condition}

The input variable of the fuzzy logic controller is dependent entirely on the temperature sensor. The sensor range should be wide enough to account for climatic and regional fluctuations. The proposed model works at any temperature within range $(0-50)^{\circ} \mathrm{C}$ as given in Table 1 and shown in Fig.1.

The motor-speed is categorized into: (1) Nearly Stop (2) SLOW (3) Medium (4) Fast. If the current temperature of the room is above the desired temperature then this motor automatically varies its speed according to temperature difference as given in Table 2 and shown in Fig.2.

MATLAB simulation was adapted according to the arrangement of membership functions for five rules as given in Table 3 and shown in Fig.3.

This system was simulated for the given range of input variables. In this design model, the speed of motor depends upon the selected value of temperature sensor. Fuzzy inference rules map between the input variables of the temperature and the input variables of the motor speed to get the output motor speed dedicated to the reading of the temperature sensor as shown in Fig.4.

\section{B. Fuzzy Controller design for Lighting System}

The proposed system is designed to automate on/off light according to the occupancy of a room or a hall by using Passive Infra-Red (PIR) sensor. The input variable of the fuzzy logic controller is two PIR sensors placed to avoid false detection, which leads to unnecessary switching on/off due to motion. This sensor is a digital sensor and TTL compatible. Thus, it gives logic ' 1 ' for motion and logic ' 0 ' when there is no motion. MATLAB simulation was adapted according to the arrangement of membership functions for the four rules as given above in Table 4 and shown above in Fig.5.

The lamps were controlled individually by switching them on or off by the controller. On the other side, by using the controller, energy can be saved up to around $23.9 \%$ [9]. These results proved that the proposed controller could contribute in increasing energy usage efficiency [10].

\section{SYSTEM DESIGN}

The system consists of several nodes namely: smart meter node, monitor motion detection \& control Light (on/off) node, monitor temperature \& control motor speed node and web application. The complete proposed system architecture is illustrated in Fig.6. The function of every node is detailed below.

\section{A. Smart Meter Node}

The smart metering module collects data from the building with the help of suitable integrated sensors. Then it uses the WiFi module to send the collected data to the control room. The system was designed as a SBC using (Raspberry Pi), used as a control web application. 
The operating system used in Raspberry $\mathrm{Pi}$ is Linux. It has the capability to communicate with the smart meter via WiFi network without additional cost and complexity of a gateway, controls the operation of the appliances according to the analysis of received data. Through the web application, commands can be initiated to access the appliances parameters and tune them.

\section{B. Control and monitor Light Circuit}

Lighting control is an effort to reduce power waste when the room is not occupied, by using occupancy sensors within lighting systems to turn off the lights automatically when the room is empty. PIR sensor is used to detect a motion. The sensor readings are used to turn off the lights if there is no activity and turn on the lights otherwise. When there is suspicious movement detected by PIR Sensor, it serves as an input for 4-channel relay connected with lamp to turn on/off the light. Fig.7(a) illustrates the connection circuit while Fig.7(b) shows the flow chart of controller code.

\section{Control and monitor Air Condition (AC).}

DHT22 temperature sensor was used for temperature measurements, after applying the fuzzy algorithm. Commands will be initiated in response to temperature readings to control $\mathrm{A} / \mathrm{C}$ motor speed. The connection circuit between microcontroller with temperature sensor and the motor is shown in Fig.8(a) Connection circuit, while Fig.8(b) is the Flow chart.

\section{Control Web Application}

This is the most important part as it is the programming software which allows the user to interact with the information from smart meter and perform mathematical calculations according to these measurements, hence initiating commands to access parameters such as: changing operational modes, changing (acceleration/ deceleration) patterns of motor and controlling (lighting \& appliances). Web monitor displaying the status of building condition is shown in Fig.9.

Based on this figure, it can be seen that there are 7 buttons: the first one is for manual mode, the second button is used in automatic mode. There are 5 other buttons, in manual mode two of them are to control lights turn (on/off), and the other 3 buttons are used to activate the speed of the motor (high speed, medium speed and off). There is a monitor below the button status showing room temperature, current consumption of light, current consumption for $\mathrm{A} / \mathrm{C}$ motor and total power consumption.

\section{Experimental Testbed}

Some experiments have been conducted to check system reliability and performance. Experimental testbed consists of two parts, the first part to control light circuit by using Lamp 100 watt, PIR motion detection sensor and 4-channel relay. Tests are performed in lab by checking the motion detection sensor and relay performance to activate / deactivate the lamp. The second part to control the speed of the motor of $A / C$ by using $D C$ motor instead of the motor of $A / C$. The specification of this DC motor is (RPM: 300 at $12 \mathrm{~V}$, Voltage: $4 \mathrm{~V}$ to $12 \mathrm{~V}$, Current consumption on no load=0.7A and on load $=4.8 \mathrm{~A}$, Motor weight: $280 \mathrm{gm}$ ). The power applied to the DC motor can be controlled by regulating the amount of voltage across motor terminals by using "Pulse Width 
Modulation". By changing or modulating the timing of these pulses the speed of the motor can be controlled, ie, the longer the pulse is "ON", the faster the motor will rotate and likewise, the shorter the pulse is "ON" the slower the motor will rotate. In addition, temperature/humidity sensor sends the read values to the microcontroller. Also, testing the motor speed by detecting the variation of its speed according to the temperature values. Finally, testing function buttons used in web application. Table 5 shows these test results and Fig.10 shows the experimental testbed.

\section{NETWORK SIMULATION}

Network simulation has been done to achieve network performance and to provide an accurate understanding of system behavior by measuring throughput, traffic drops and end-to-end delay using OPNET network simulator.

The proposed system of the simulation design is based on four different scenarios. The first one is from smart meter to controller. The second one is form sensor to controller. The third one is from controller to actuator. The last one is from smart device to controller.

Results from these scenarios show that there is no packet drop during the communication between building equipment and monitoring devices as shown in Fig.11. Packet drop occurred when it exceeded 8000 bytes, as shown in Fig. 12.

Table 6 illustrates the values of the end-to-end delay for the four scenarios. Throughput of the designed system is $100 \%$ in case of no traffic drop while it is $50 \%$ at packet drop.

\section{Conclusion}

This paper has presented the design of a BMS prototype. The system comprises a microcontroller, SBC and a web application, which can be accessed by a PC or a smart phone. Fuzzy algorithm has been implemented to enhance system efficiency and to show the advantage of fuzzy logic utilization in the studied scenarios. In case of the $A / C$ system, fuzzy logic helps to solve a complex problem without getting involved in intricate relationships between physical variables. It also proposes a fuzzy logic controller to automate the lighting system and demonstrates that the BMS via WLAN network has been successfully designed. The designed system has been tested, lighting switching and motor speed can be controlled via the internet with reliability and results were displayed and controlled by multi-type devices. Experimental results show the achievement of both the performance and reliability of the system. Finally, throughput, traffic drops, and end-to-end delay have been measured to ensure network performance. 


\section{Figures}

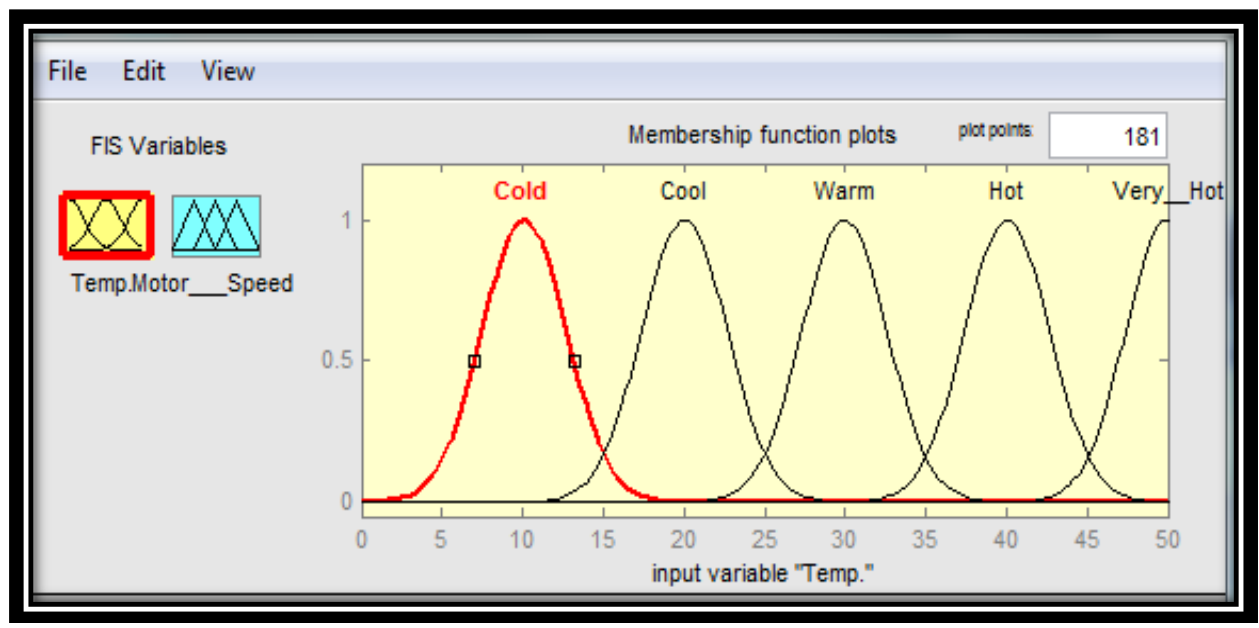

Fig. 1: Plot of membership function of current temperature

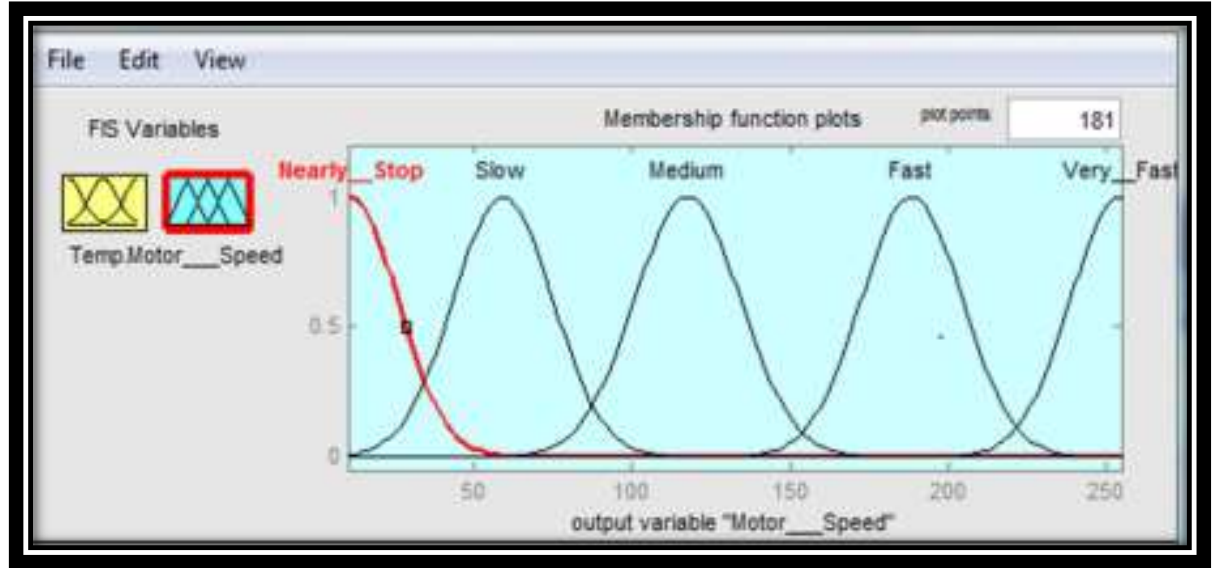

Fig. 2: Plot of membership function of motor speed 


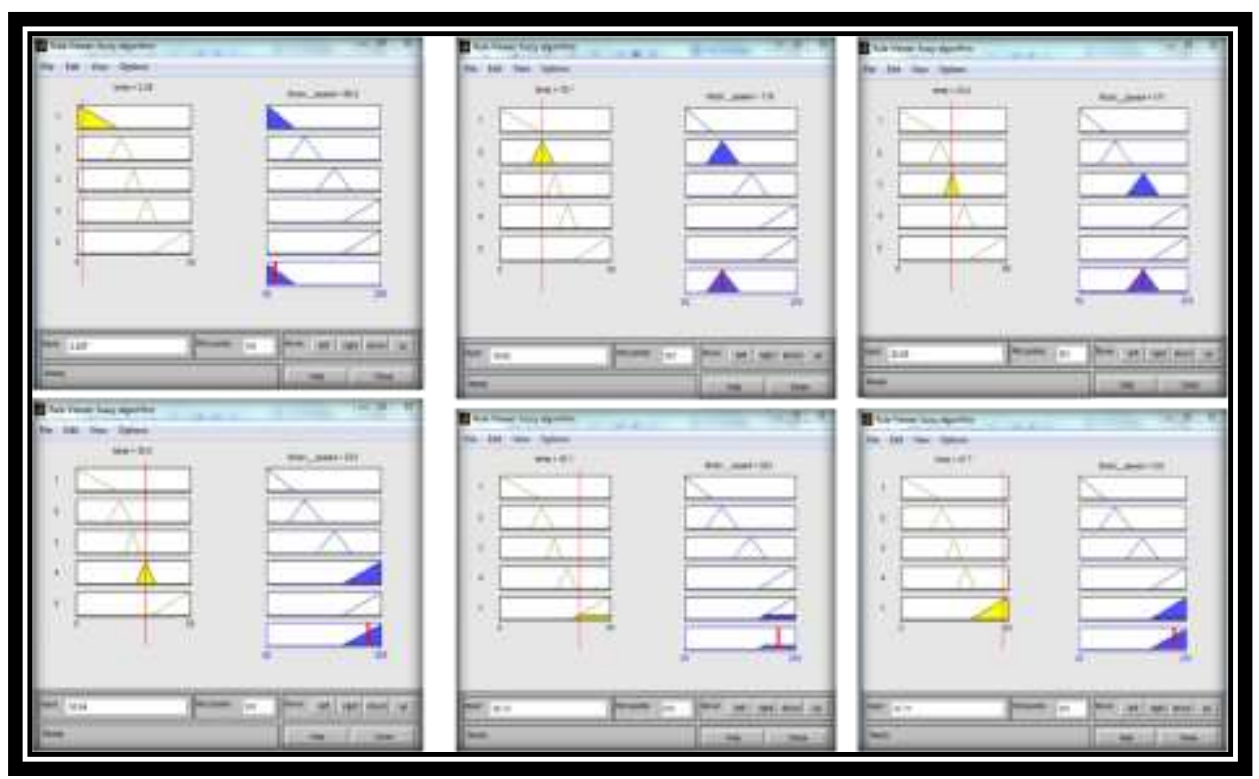

Fig. 3: Rule viewer of Fuzzy algorithm

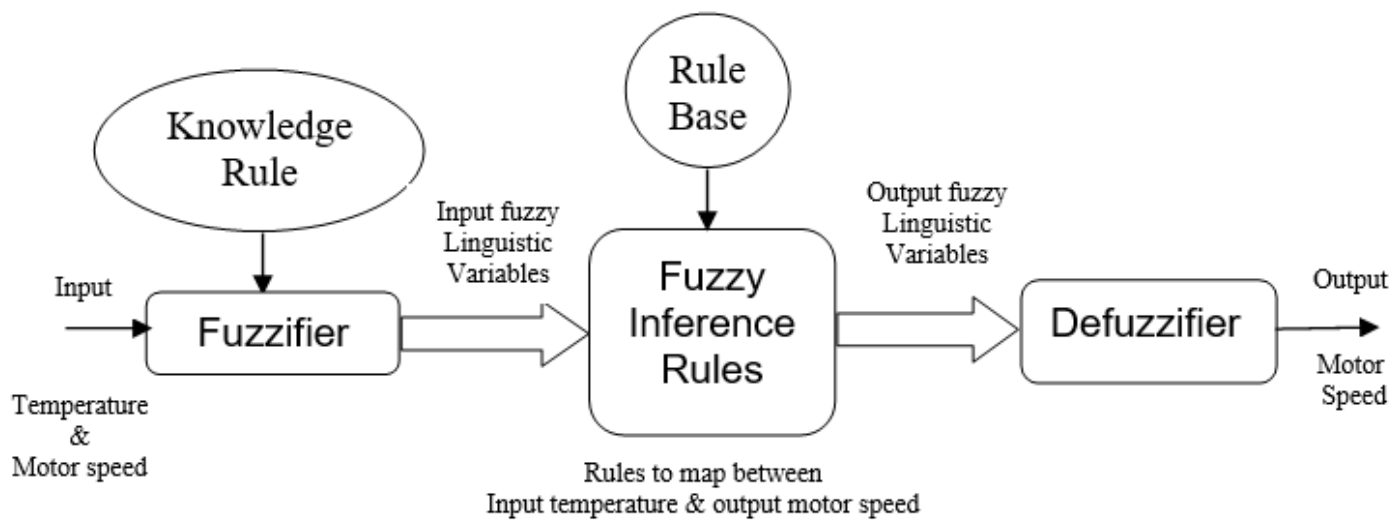

Fig. 4: Fuzzy logic process for motor speed of air condition 


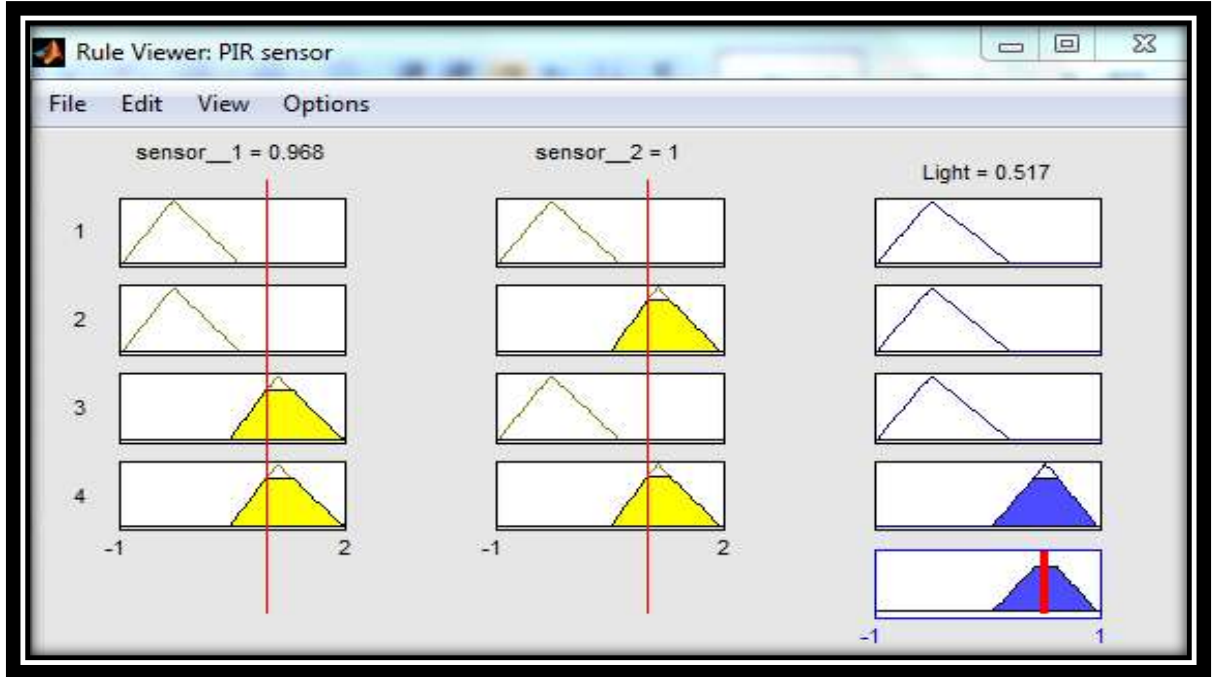

Fig. 5: Rule viewer of Fuzzy algorithm
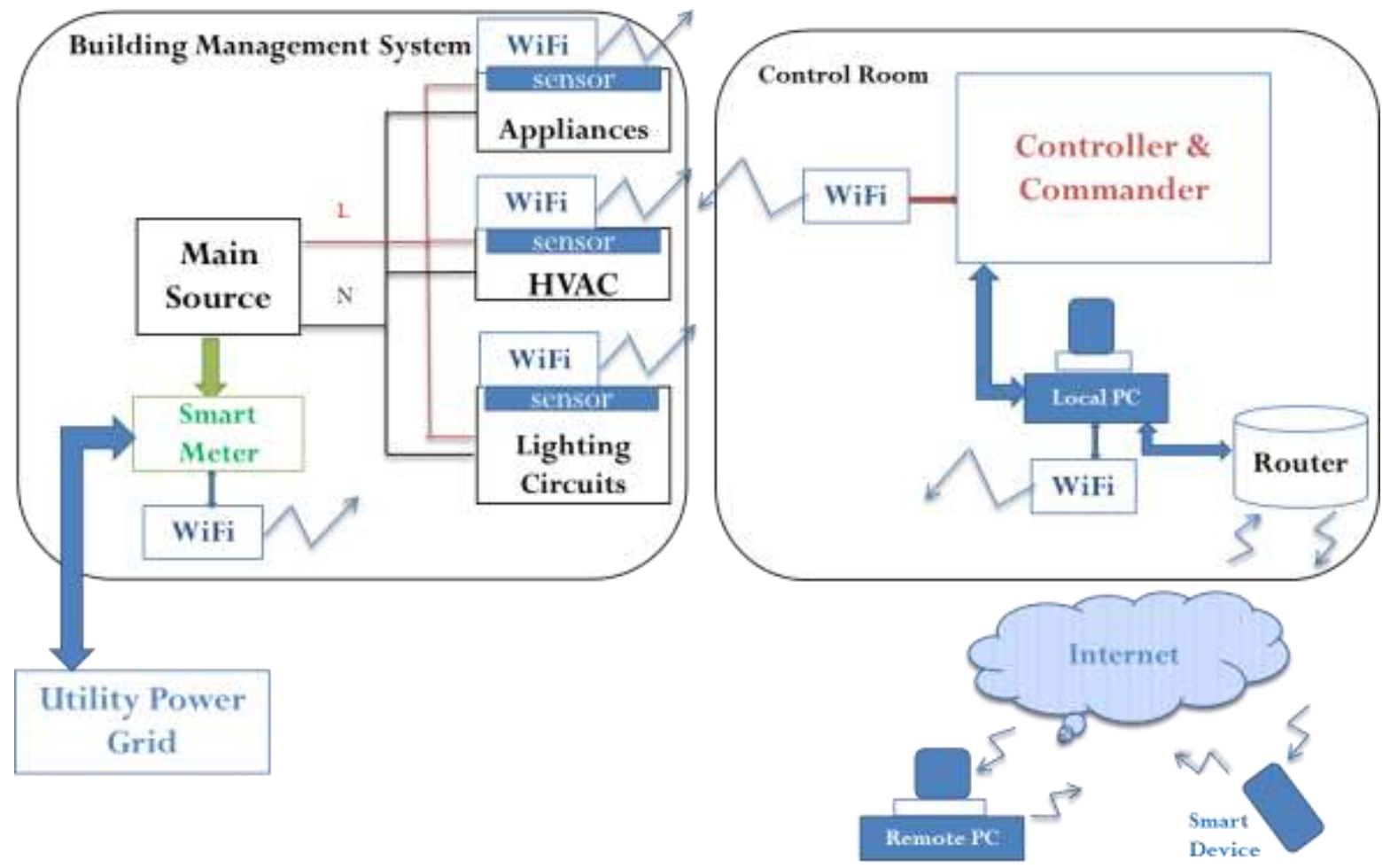

Fig. 6: Block Diagram of Proposed System 


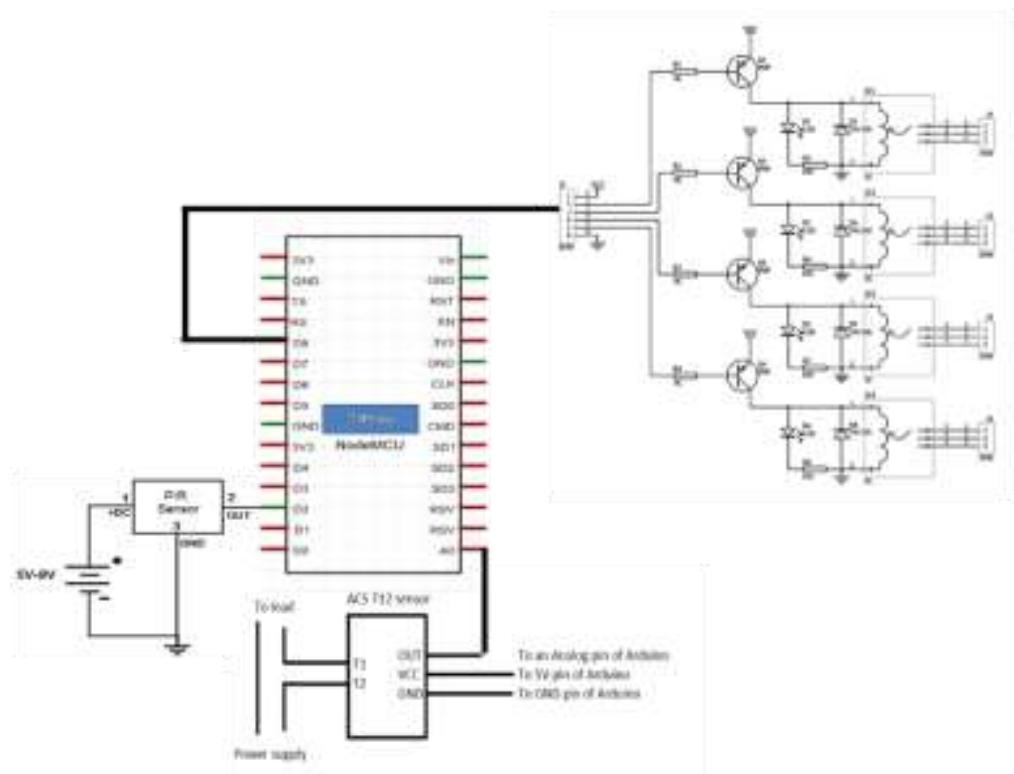

Fig. 7: (a) Schematic of the PIR Sensor Circuit

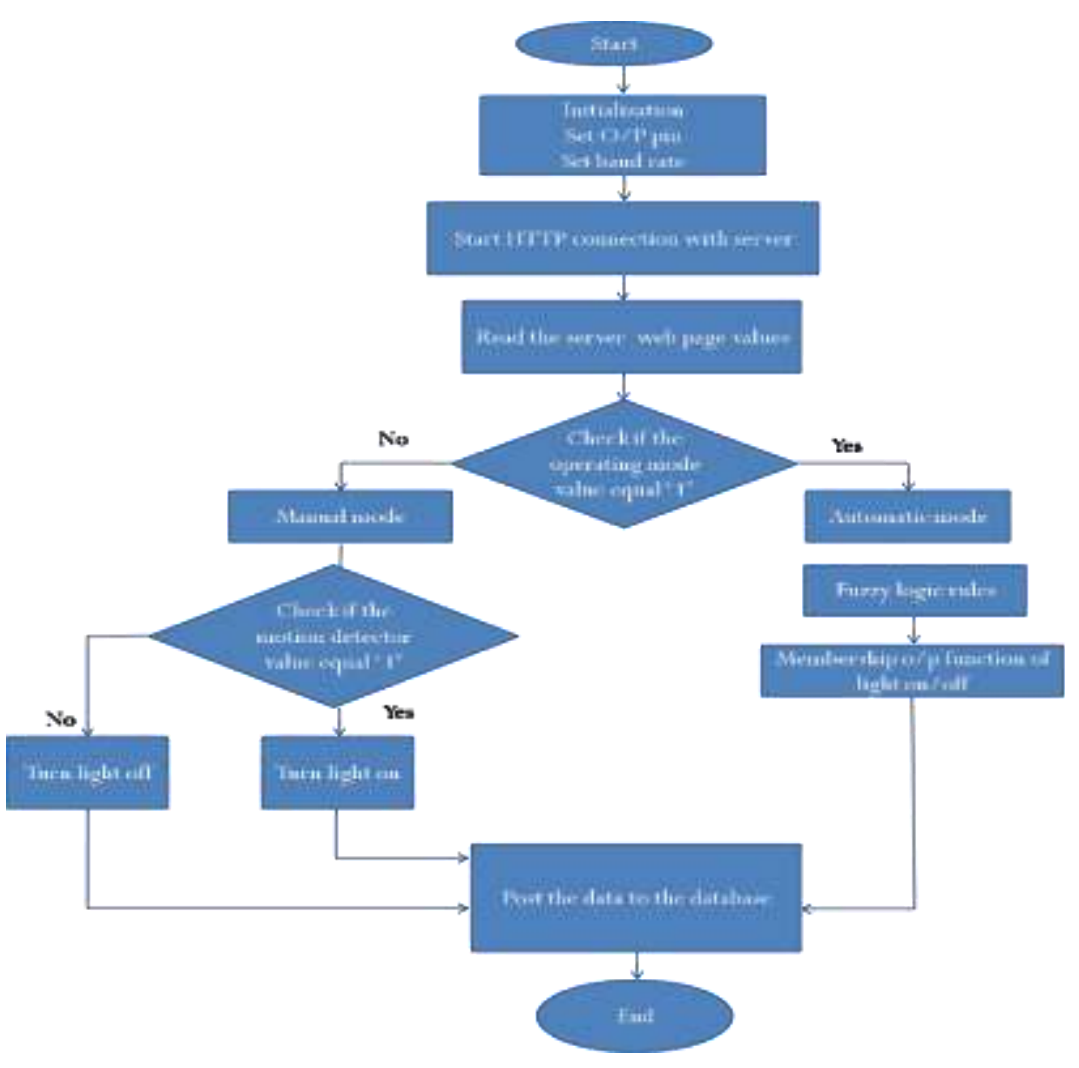

Fig. 7: (b) Flow chart of controller code 


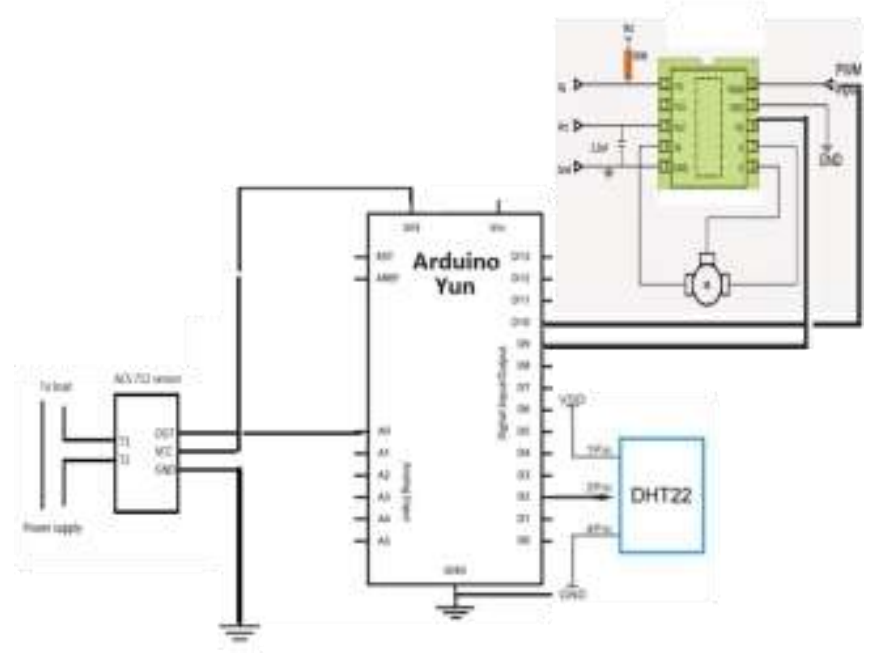

Fig. 8: (a) Schematic of the motor driver and the temperature sensor

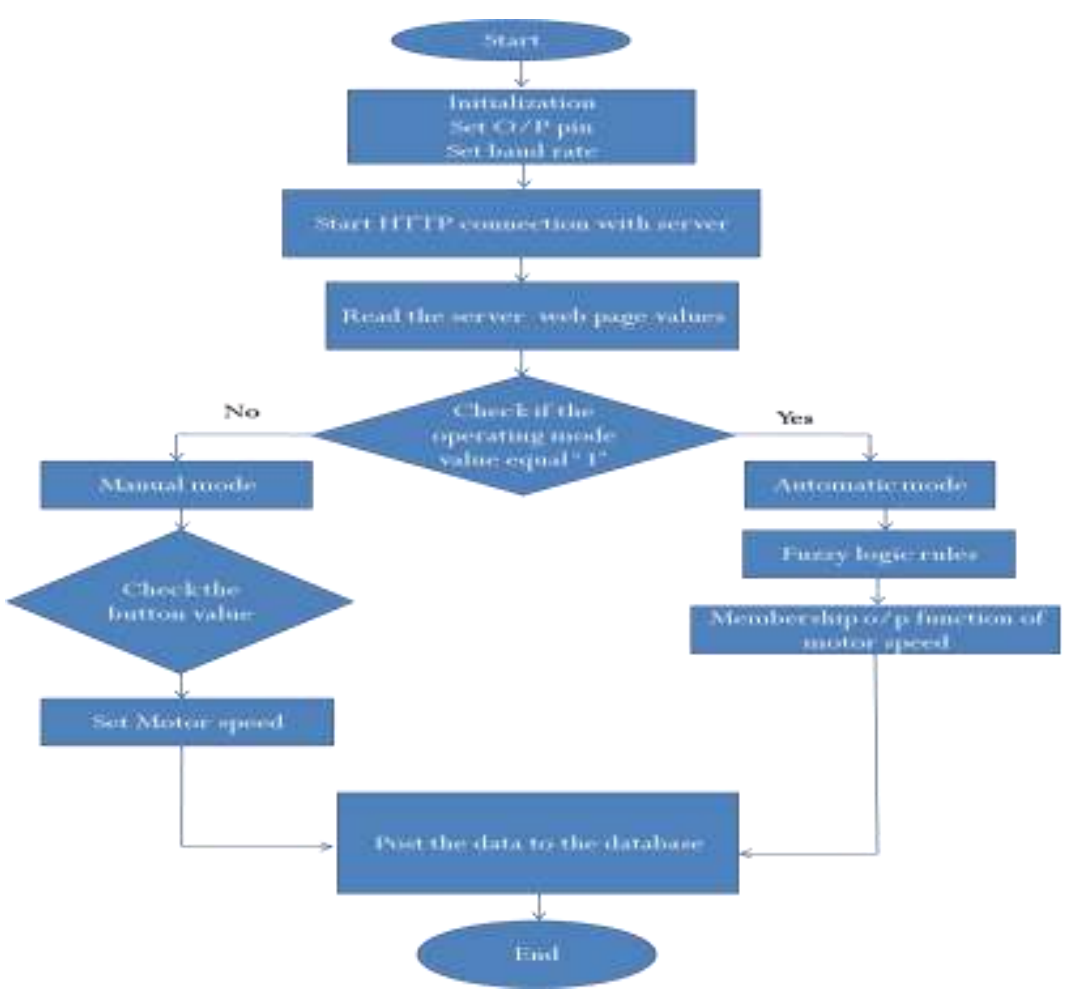

Fig. 8: (b) Flow chart of controller code 


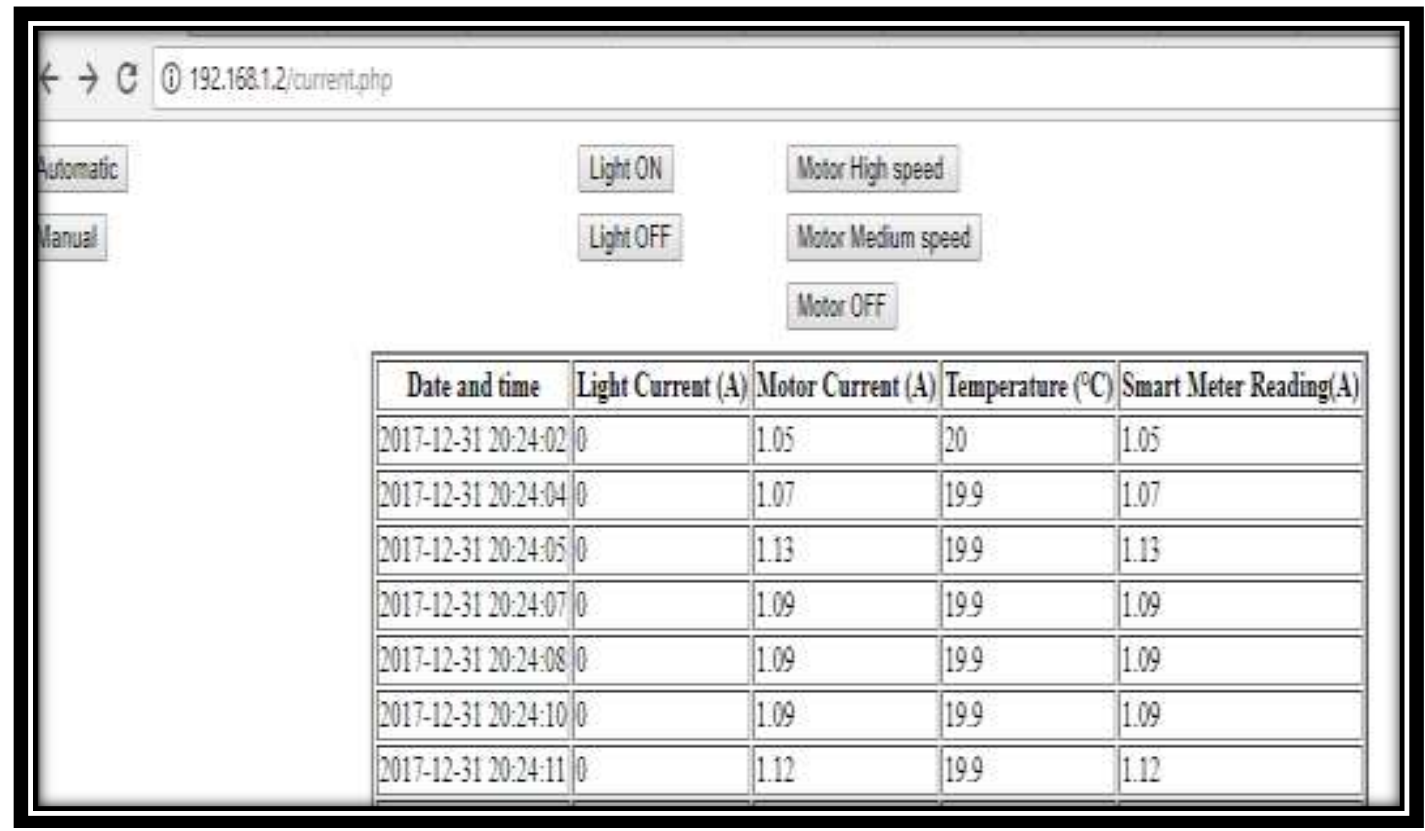

Fig. 9: Web application

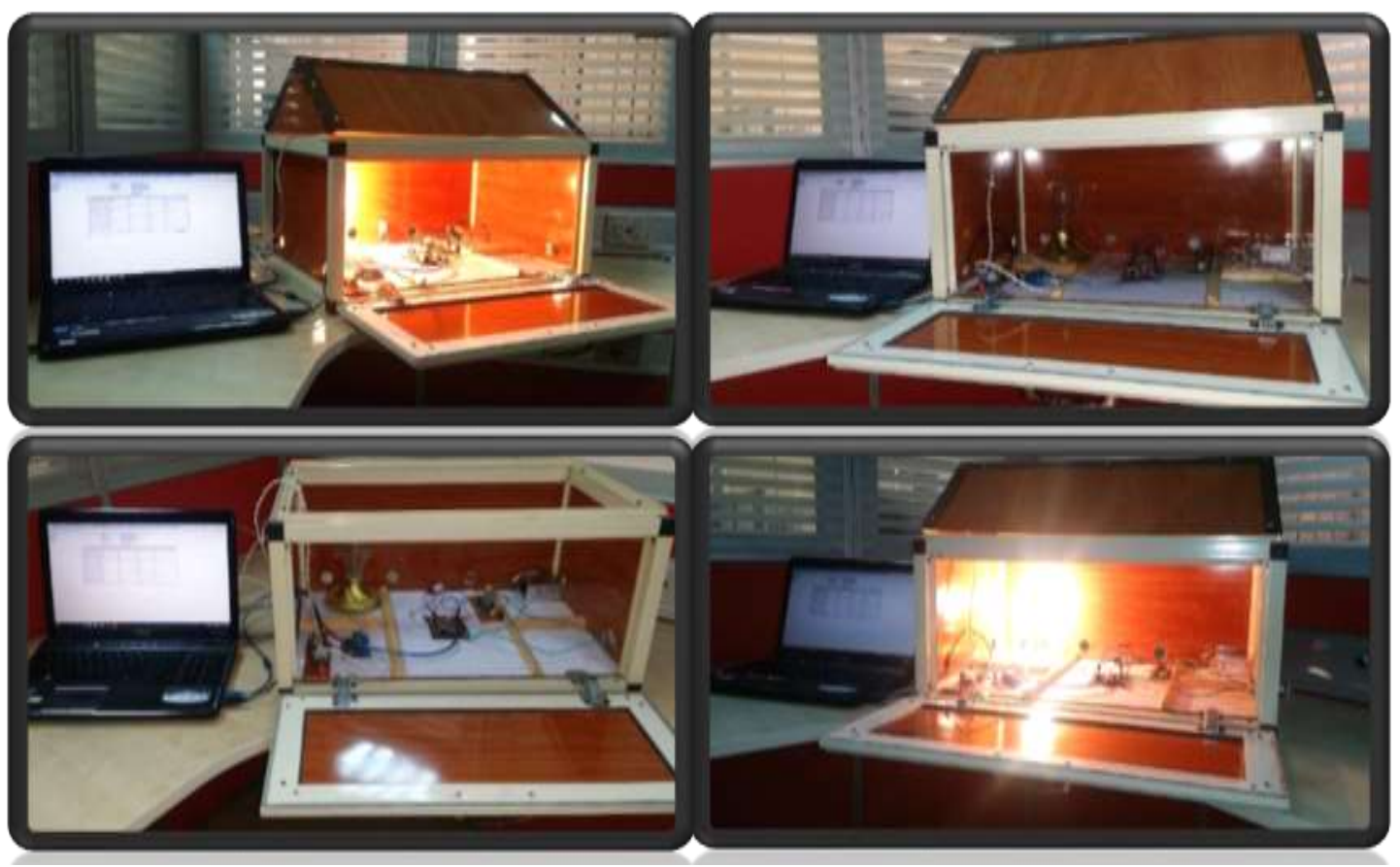

Fig. 10: Experimental testbed 


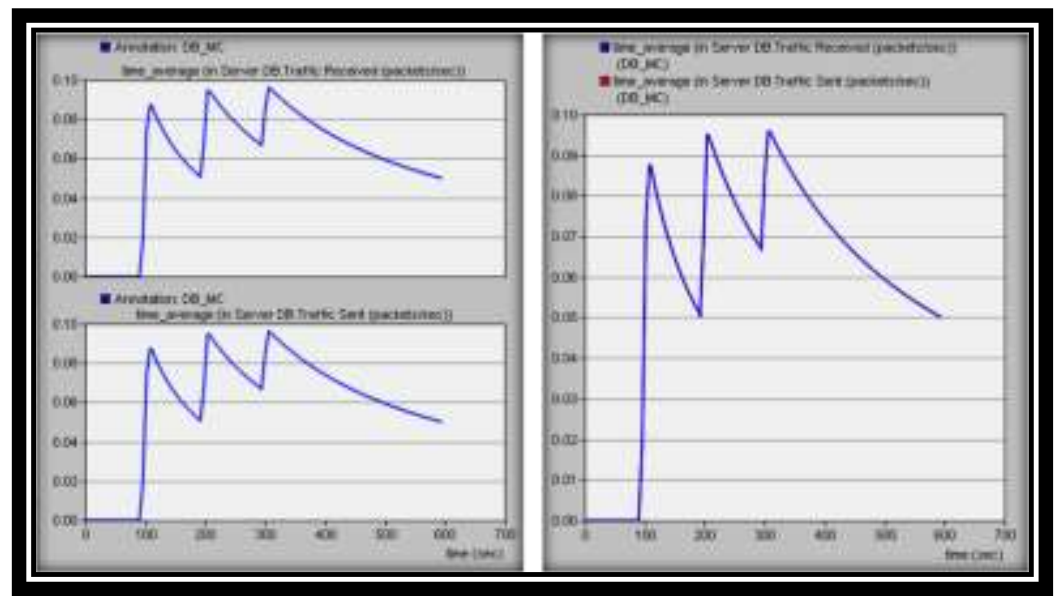

Fig. 11: Time average of traffic sent and received from smart meter to controller at packet size (8000) bytes

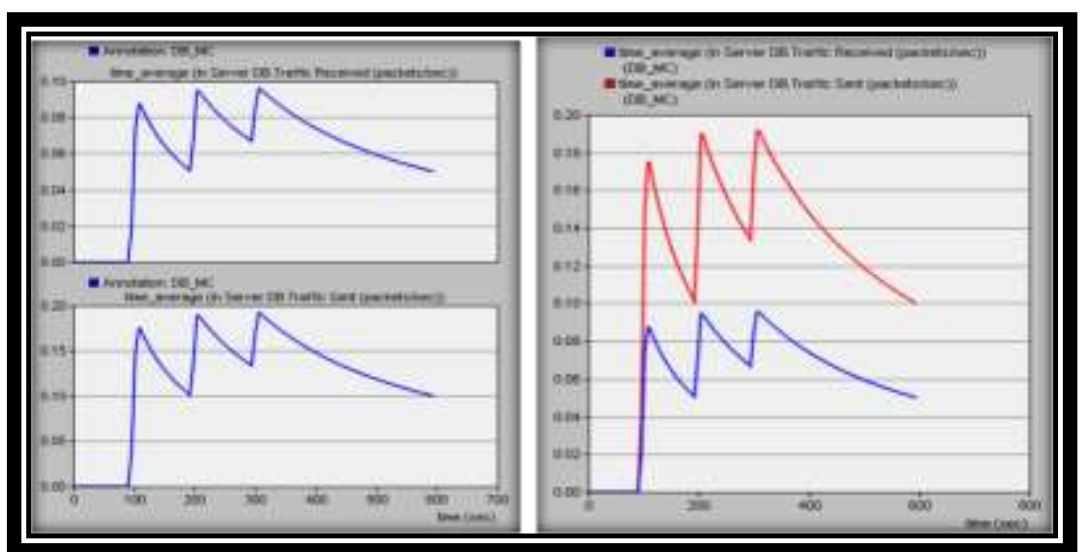

Fig. 12: Time average of traffic sent and received from smart meter to controller at packet size more than (8000) bytes

\section{Tables}


Table 1: Membership Functions for Current-Temperature

\begin{tabular}{|c|c|}
\hline MEMBERSHIP FUNCTIONS & RANGE $\left({ }^{\circ} \mathrm{C}\right)$ \\
\hline \hline Cold & $(00-15)^{0} \mathrm{C}$ \\
\hline Cool & $(14-24)^{0} \mathrm{C}$ \\
\hline Warm & $(22-35)^{0} \mathrm{C}$ \\
\hline Hot & $(33-44)^{0} \mathrm{C}$ \\
\hline Very hot & $(42-50)^{\circ} \mathrm{C}$ \\
\hline
\end{tabular}

Table 2: Membership Function For "motor-speed"

\begin{tabular}{|c|c|}
\hline MEMBERSHIP FUNCTIONS & RANGE (PWM) \\
\hline \hline Nearly stop & $(0-30)$ \\
\hline Slow & $(25-80)$ \\
\hline Medium & $(70-140)$ \\
\hline Fast & $(130-210)$ \\
\hline Very fast & $(200-255)$ \\
\hline
\end{tabular}

Table 3: Rules editor of the fuzzy algorithm

\begin{tabular}{|c|c|}
\hline Temperature & Motor speed \\
\hline \hline If temp is cold & Motor speed is nearly stop \\
\hline If temp is cool & Motor speed is slow \\
\hline If temp is normal & Motor speed is medium \\
\hline If temp is hot & Motor speed is fast \\
\hline If temp is very hot & Motor speed is very fast \\
\hline
\end{tabular}

Table 4: Rule editor of fuzzy algorithm

\begin{tabular}{|c|c|c|}
\hline Sensor 1 & Sensor 2 & Light \\
\hline \hline Low & Low & Off \\
\hline Low & High & Off \\
\hline High & Low & Off \\
\hline High & High & On \\
\hline
\end{tabular}

Table 5: Results of the experimental testbed 


\begin{tabular}{|c|c|c||c|c|}
\hline No. & Test & Function & Procedure & Result \\
\hline \hline 1 & Sensor PIR 1 & $\begin{array}{c}\text { Used for lamp } \\
\text { activation }\end{array}$ & $\begin{array}{c}\text { Lamp will on when any move } \\
\text { detected }\end{array}$ & Ok \\
\hline 2 & Sensor PIR 1 & $\begin{array}{c}\text { Used for lamp } \\
\text { deactivation }\end{array}$ & $\begin{array}{c}\text { Lamp will off when no movement } \\
\text { detected }\end{array}$ & Ok \\
\hline 3 & DHT22 & Temp. sensor & Send data to microcontroller & Ok \\
\hline 4 & Push button 1 & $\begin{array}{c}\text { Motor high } \\
\text { speed }\end{array}$ & Motor high speed depend on button & Ok \\
\hline 5 & Push button 2 & $\begin{array}{c}\text { Motor medium } \\
\text { speed }\end{array}$ & Motor medium speed depend on & Ok button \\
\hline 6 & Push button 3 & Motor off & Motor off depend on button & Ok \\
\hline 7 & Push button 4 & Lamp on & Lamp on depend on button & Ok \\
\hline 8 & Push button 5 & Lamp off & Lamp off depend on button & Ok \\
\hline 9 & Push button 6 & $\begin{array}{c}\text { Change to } \\
\text { automatic } \\
\text { control }\end{array}$ & $\begin{array}{c}\text { All equipment controlled } \\
\text { automatically via fuzzy logic control }\end{array}$ & Ok \\
\hline 10 & Push button 7 & $\begin{array}{c}\text { Manual mode } \\
\text { manually via push buttons or smart } \\
\text { device }\end{array}$ & Ok \\
\hline
\end{tabular}

Table 6: End-to-End delay

\begin{tabular}{|c|c|c|}
\hline No. & Scenario & End-to-End delay \\
\hline \hline 1 & From smart meter to controller & 0.017 second \\
\hline 2 & From sensor to controller & 0.005 second \\
\hline 3 & From controller to actuator & 0.009 second \\
\hline 4 & From smart device to controller & 0.04 second \\
\hline
\end{tabular}




\section{Reference}

[1] S. Tanga, V. Kalavallya, K.Y. Nga, J. Parkkinenba,"Development of a prototype smart home intelligent lighting control architecture using sensors onboard a mobile computing system", Energy and Buildings Vol. 138, pp. 368-376, (2017).

[2] A. Zanella, N. Bui, A. Castellani, "Internet of Things for Smart Cities", IEEE Communications Society, Vol. 1, no. 1, pp. 22-32, (2014).

[3] S. Jain, V. Kumar, A. Paventhan, "Survey on smart grid technologies- smart metering, loT and EMS", IEEE Electrical, Electronics and Computer Science (SCEECS), pp. 1-6, (2014).

[4] K. M. Aldali, S. Moustafa, "An attempt to achieve efficient energy design for HighIncome Houses in Egypt: Case Study: Madenaty City" International Journal of Sustainable Built Environment Vol. 5, Issue 2, pp. 334-344, (2016).

[5] A. Adriansyah, A.W. Dani," Design of Small Smart Home System Based on Arduino" IEEE Electrical Power, Electronics, Communications, Controls, and Informatics Seminar (EECCIS), (2014).

[6] S.M. Patel and S.Y. Kanawade, "Internet of Things Based Smart Home with Intel Edison", International Conference on Communication and Networks, (2017).

[7] G.R. Mounisha, K. Bouddupally, M. Lakha, "IoT Based Energy Efficient Smart Buildings with Safety System", International Journal of Scientific Engineering and Technolgy Research, Vol. 5, Issue 9, pp. 2898-2901, (2017).

[8] T. Kumar, Y. Das, "Design of A Room Temperature and Humidity Controller Using Fuzzy Logic", American Journal of Engineering Research (AJER), (2013).

[9] A. Hartoyo and S.D. Panjaitan, "Development of Automation System for Room Lighting Based on Fuzzy Logic Controller", International Journal of Information and Electronics Engineering, Vol. 2, No. 6, (2012).

[10] P.W. Mutua, Prof. M. Mbuthia, "Intelligent Lighting System Design with Fuzzy Logic Controller", International Journal of Electronics \& Communication Technology (IJECT), (2015). 